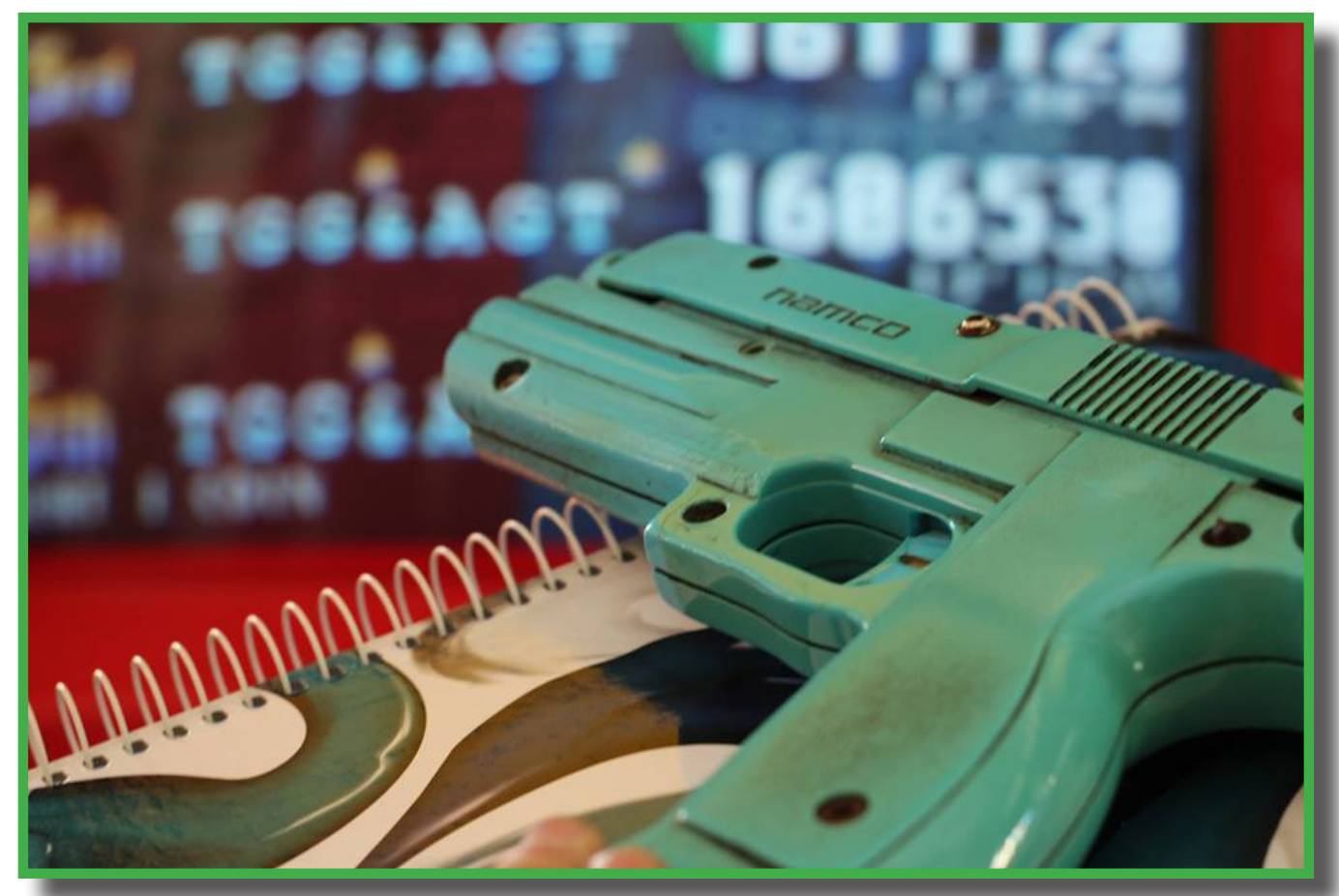

Fotografia de Lúcio Canabarro (2013), mestre pela UFPEL, canabarro@ymail.com 


\title{
Para Além dos Reducionismos Educacionais: Estudo de Caso Sobre as Apropriações dos Jogos Eletrônicos Entre Crianças de 6 a 9 Anos em uma Escola do Município de Cianorte - PR (2012)
}

\author{
Adriély da Silva Santos \\ Graduada em Pedagogia pela Universidade Estadual de Maringá. Ao longo da graduação, foi bolsista pela \\ Fundação Araucária.
}

\begin{abstract}
ResUMo
O presente artigo analisa as apropriações infantis em relação aos jogos eletrônicos, atinando, também, para as práticas expressas pelas crianças. Busca-se desconstruir os preconceitos do campo científico e escolar referentes aos games, problematizando as relações entre o instrumento midiático e a educação. A amostra foi composta por trinta e uma crianças entre aproximadamente 6 a 9 anos de idade que estudam em uma escola de Ensino Fundamental localizada em São Lourenço, distrito da cidade de Cianorte (Paraná), no ano de 2012. Os alunos foram analisados por meio de tratamentos qualitativos em um estudo de caso no qual se utilizou como metodologia entrevistas semiestruturadas, permitindo um diálogo "aberto" com as crianças e a possibilidade de adaptação da entrevista de acordo com as eventuais informações que foram encontradas no decorrer da investigação. Do ponto de vista teórico, foram utilizados os conceitos de representação e apropriação propostos por Roger Chartier, bem como algumas premissas da área da educomunicação.
\end{abstract}

Palavras-chave: Jogos eletrônicos. Infância. Educação.

\begin{abstract}
This paper intends to analyze the infant appropriations of electronic games, realizing, also, to the practices expressed by the children. It seeks to deconstruct the prejudices of scientific and educational field related to games, questioning the relations between this media tool and education. The sample was composed by thirty-one children between, approximately, 6 and 9 years old studying at an elementary school located in São Lourenço, city of Cianorte's district (Paraná), in 2012. Students were analyzed by qualitative approaches in a case study in which it was utilized like methodology semi-structured interviews, allowing an "open" dialogue with the children and the possibility of interview's adaptation according to any information that was found in the development of the research. From theoretical perspective, it was utilized the concepts of representation and appropriation suggested by Roger Chartier, as well as some premises of educomunication's field.
\end{abstract}

Keywords: Electronic games. Childhood. Education. 


\section{Introdução}

$\mathrm{Na}$ contemporaneidade, vemonos rodeados por um mundo tecnológico e comunicacional no qual o acesso à informação se torna cada vez mais fácil, rápido e encontra-se disponível a parte significativa das pessoas, atingindo não somente o público adulto, mas também infanto-juvenil. Neste cenário, observa-se que, desde muito pequenas, as crianças são expostas ao universo midiático, composto por uma imensa variedade de informações, desde propagandas em outdoors, na TV, em panfletos, na Internet, entre outras possibilidades. Constituímo-nos como parte deste cenário, uma vez que número significativo de pessoas se veste de acordo com modelos prescritos por esse universo comunicacional, com os quais se identifica ou simplesmente se sente confortável. Nesse emergente meio ambiente comunicacional, pode-se constatar uma mutação nos modos de circulação do saber, que passa a ser veiculado também por mídias como a televisão e a Internet. Dessa maneira, o conhecimento transcende os livros e os ambientes escolares, tornando o aprendizado contínuo e não destinado apenas a crianças e jovens (MARTíN-BARBERO, 2008).

Em meio a todas as modificações tecnológicas e comunicacionais existentes na sociedade, bem como nas transformações ocorridas na maneira de viver, percebe-se que a infância também veio a adquirir um novo caráter, no qual as crianças têm "novos brinquedos" e novas "brincadeiras" como, por exemplo, os jogos eletrônicos. Como demonstram Shiley Steinberg e Joe Kincheloe (2004, p. 14), essas modificações geradas na infância exigem que examinemos as suas causas. Nesse sentido, a pedagogia cultural ${ }^{1}$ “[...] enquadra a educação numa variedade de áreas sociais, incluindo, mas não se limitando à escolar [...]". Como demonstra Vera Barros de Oliveira (2000, p. 30), ao discutir a importância da tecnologia na contemporaneidade:
[...] A evolução das técnicas acompanha toda a escalada social humana e faz parte inerente também do desenvolvimento infantil. A criança só se desenvolve se vier a se inserir em seu meio, em seu tempo, em sua cultura, inclusive com a utilização eficaz e criativa de sua tecnologia. Cada época tem sua riqueza e desafios.

Assim, não há como negligenciar o fato de que estes artefatos culturais exercem importante papel na formação dos indivíduos, uma vez que a psique humana se desenvolve por meio do processo de inserção do sujeito na cultura e nas relações sociais (BOOK, 2004), principalmente da criança, que está em processo de formação da identidade. Como afirma Cláudio Lúcio Mendes (2006, p. 16), "[...] participamos dos jogos constituindo com eles relações diversas: construímos e somos construídos por tais relações. Somos convencidos, por meio das histórias, das narrativas e dos personagens dos jogos, dos prazeres e dos riscos [...]". Desta maneira, deve-se levar em consideração que os seres humanos constroem permanentemente a sua identidade e, portanto, esta não é algo pronto e acabado, estando em constante processo de construção.

Considerando essas discussões, a escolha por analisar as apropriações ${ }^{2}$ dos jogos eletrônicos relaciona-se ao fato deles ganharem cada vez mais espaço e preferência não só entre o público infantil, mas também entre os adolescentes e adultos. Outra razão que justifica a escolha está ligada ao crescente debate sobre a inserção dos videogames na vida das crianças, incluindo o papel que desempenham no comportamento social que 
os alunos desenvolvem no ambiente escolar.

Temos presenciado na sociedade níveis de violência cada vez mais elevados e crimes desumanos que escapam à compreensão das causas que levam a determinadas reações. Em meio à situação, geralmente os instrumentos midiáticos, como a televisão e os jogos eletrônicos, são apontados como causas para comportamentos socialmente inaceitáveis, sem problematizar questões como a presença ou ausência da família na vida dos indivíduos ou as variáveis sociais e econômicas. Tendo em vista essas questões, serão analisadas e problematizadas as relações existentes entre jogos eletrônicos, educação, formação e sociedade. Procurase desconstruir preconceitos e estereótipos negativos relacionados aos jogos eletrônicos, geralmente convertidos em "bodes expiatórios" dos comportamentos não compreendidos socialmente. Busca-se problematizar a ideia, geralmente repetida por pais e professores acriticamente, analisando a questão sob outro olhar e compreendendo outras variáveis inerentes às apropriações dos jogos eletrônicos pelas crianças.

Considerando todos esses aspectos, esta pesquisa tem por objetivo analisar as apropriações dos jogos eletrônicos por crianças que subscrevem a faixa etária de aproximadamente seis a nove anos, em uma escola de Ensino Fundamental localizada em São Lourenço, distrito da cidade de Cianorte (Paraná), no ano de 2012. Para isso, foi realizado um estudo de caso no qual os alunos foram entrevistados por meio de um questionário aberto (THOMPSON, 1998). Vale ainda ressaltar que esta pesquisa teve o apoio financeiro da Fundação Araucária de Apoio ao Desenvolvimento Científico e Tecnológico (FAADCT/PR).

\section{As mídias eletrônicas e o "desaparecimento" da infância}

Neil Postman (1999), Steinberg e Kincheloe (2004) abordam em suas obras como a infância constitui produto social e cultural, pois foi construída historicamente. Observa-se que a concepção de infância e a própria criança modificaram-se ao longo da história. Atualmente, vivemos num período de revolução tecnológica e comunicacional, ocorrendo uma mutação nos modos de disseminação e circulação do saber, que passa a ser veiculado por outras formas além dos meios ditos escolares, acadêmicos e científicos.

Nesse sentido, Postman (1999) afirma que a televisão revelaria segredos "nocivos" à infância, uma vez que disponibilizaria as mesmas informações a todas as pessoas, independente da idade. Segundo o autor (POSTMAN, 1999, p. 93), "[...] as crianças começam a ver TV com atenção sistemática aos três anos, idade em que têm seus programas favoritos, podem cantar os comerciais e pedem produtos que vêem anunciados". As crianças são expostas desde muito pequenas às programações e comerciais ofertados pela televisão, que costumam revelar os ditos "segredos" da vida adulta.

Em contrapartida às conclusões de Postman e partindo do conceito de apropriação proposto por Chartier (2001), embora a mídia exerça influências sobre as crianças, ou seja, construa representações (CHARTIER, 1990) sobre comportamentos, ela não possui o poder de "controlá-las", isto é, de inculcar valores, crenças e costumes que determinem a conduta do indivíduo pelo resto de sua vida, como se ele fosse um ser acrítico e incapaz de construir leituras de mundo. É necessário ir além dos olhares 
limitados e reducionistas, transcendendo os preconceitos e buscando compreender a teia de relações que envolvem a formação do ser humano atualmente, pois somos pessoas que constroem suas identidades no decorrer da vida. O homem é sujeito histórico, como aponta Alexei Leontiev (apud BOOK, 2004, p. 267)

[...] não há aptidões e características especificadamente humanas que tenham sido transmitidas por hereditariedade biológica; todas foram adquiridas no decurso da vida por um processo de apropriação da cultura criada pelas gerações precedentes [...].

Diante disso, deve-se adotar um olhar reflexivo e sensível sobre a formação do ser humano, principalmente na fase da infância, buscando conhecer e compreender os múltiplos fatores que agem sobre ela, sem esquecer que cada pessoa é única e, por isso, apresenta maneiras diferentes de ver, sentir e agir sobre o mundo. Portanto, faz-se necessário, ao analisar as práticas das crianças em ambiente escolar, levar em consideração todas as possíveis variáveis que influem em seu comportamento.

Certos pesquisadores têm afirmado os malefícios inerentes aos jogos eletrônicos. Valdemar W. Sertzer (2011) descreve alguns dos possíveis efeitos sobre a saúde do ser humano, como, por exemplo: o excesso de peso, problemas de atenção e hiperatividade, agressividade, comportamento antissocial, medo, entre outros. Entretanto, os "possíveis efeitos" não são causados necessariamente pelos jogos eletrônicos, mas por um conjunto de fatores que os transcendem. Uma pessoa pode jogar videogames, praticar esportes, ser um bom filho, pai ou namorado e ser saudável. Nesse caso, os jogos eletrônicos são tomados como "bodes expiatórios", levando para a linguagem científica, sem maiores problematizações, postulados reducionistas do senso comum. Desse modo, não se deve generalizar e muito menos classificar os jogos eletrônicos e demais mídias como apenas nefastas ao ser humano, uma vez que somos sujeitos constituídos pelas relações estabelecidas com o nosso meio. As mensagens midiáticas podem sugerir comportamentos, porém não há como negligenciar outras variáveis que podem causar os problemas descritos.

As mensagens midiáticas podem sugerir determinadas representações, mas não é possível determinar leituras estanques. Há uma série de fatores envolvidos nas relações entre autor, texto e leitor, relembrando que o ser humano não é uma marionete ou um objeto passivo que apenas recebe informações e as incorpora como verdades absolutas que devem guiar sua vida. Pelo contrário, de acordo com a cultura na qual está inserido, com o tipo de educação que recebe, por meio dos seus "gostos", com os modelos com os quais se identifica e com uma variedade de outros elementos que constituem a sua vida, o sujeito se constrói agregando uma série de características, elementos e valores, advindos de seu meio e das possibilidades/oportunidades de acesso que possui, os quais dão origem ao processo de construção e reconstrução da identidade do ser humano que só termina com a sua morte.

As estruturas mentais tornam-se mais complexas de acordo com o desenvolvimento da criança. Isso ocorre principalmente através do lúdico, com o qual a criança cria conceitos a partir dos quais passa a enxergar o mundo, não necessariamente o real, mas a sua interpretação. Tendo em vista a importância das brincadeiras na constituição da personalidade infantil, é preciso atinar para o papel dos games, que constituem 
formas modernas de jogos e brincadeiras, mesmo que não exclusivamente calcados na materialidade, como variáveis na estruturação do indivíduo.

Dentre as variáveis que influenciam a rede de apropriações infantis, é possível destacar a escola e a família. De forma geral, as pessoas frequentam a escola durante doze anos ou até mais, no caso daqueles que optam pelo ensino superior. $O$ tipo de escola que frequentam, de professores com os quais têm contato fornecem subsídios, características que podem ser apropriadas por meio do processo da identificação que, por sua vez, permite, em parte, a constituição da identidade, ou seja,

[...] o que eu quero ser como mulher, por exemplo, tem como referência várias mulheres que foram importantes para mim, ao longo de minha vida: é um amálgama de características de minha mãe, daquela professora tão especial, da heroína de um romance e da mãe de uma amiga minha. Este é um modelo com o qual me identifico e vou procurando construir a minha identidade [...] (BOOK; FURTADO; TEIXEIRA, 2002, s.p).

Tendo em vista essas considerações, ao contrário do que afirma Postman (1999), a mídia não estaria fazendo a infância desaparecer. A infância, como categoria social e cultural, está se modificando, acompanhando o processo de mudança histórica da sociedade. O universo infantil vem incorporando novos valores, crenças, maneiras de se vestir, brincadeiras, enfim, criando novas maneiras de "ser criança".

\section{As relações entre tecnologia e formação}

$\mathrm{Na}$ contemporaneidade, testemunhamos uma "nova criança", que encontra na mídia uma forma de entretenimento e aprendizagem. Como demonstra uma pesquisa realizada em doze países por Millward Brown (apud RIDOLFI, 2010), as crianças brasileiras de quatro a doze anos lideram o ranking de acesso à Internet, passando cerca de treze horas online por semana. Do tempo consumido conectado, a maior parte é passada em jogos e similares. De acordo com a Internet World Stats (2011), 1,96 bilhão de pessoas tinham acesso à Internet em junho de 2010, o que representa $28,7 \%$ da população mundial. É possível que, desde então, a cifra tenha crescido.

Como vimos, é no período da infância que o ser humano constrói grande parte dos seus conceitos. Portanto, o meio social no qual a criança vive, as relações que estabelece e os meios aos quais tem acesso desenvolvem importante papel na construção da sua personalidade, na sua forma de enxergar o mundo e de agir. Geralmente, as crianças, desde o seu nascimento, são "bombardeadas" por todo esse universo midiático, pois desde muito pequenas são expostas a propagandas de TV, aos outdoors, muitas vezes aos shoppings, às marcas famosas, enfim ao nosso mundo.

Pelo fato da maioria dos pais, em virtude do mercado de trabalho, ficar fora de casa o dia todo, as crianças geralmente passam longas horas em frente à televisão, aos videogames, à Internet, entre outros meios. Isso acaba por se tornar um dos meios pelos quais a criança "conhece o mundo", tendo acesso a várias informações e construindo conceitos diferenciados sobre diversos assuntos. Paralelamente à família, a televisão e outros meios midiáticos vêm instruindo as crianças fora da escola, tornando a mídia uma terceira instituição educacional. Esses meios de comunicação constroem uma gama de cultura e, portanto, de conhecimentos, a partir dos quais as crianças aprendem e 
muitas vezes reconstroem suas experiências (STEINBERG; KINCHELOE, 2004).

Assim sendo, contemporaneamente é praticamente impossível dissociar a infância dos desenhos animados, dos filmes infantis, dos brinquedos, dos jogos e até mesmo do computador, uma vez que a tecnologia se faz tão presente em nossas vidas. Nesse contexto informacional e comunicacional, estamos rodeados e somos constituídos por um mundo tecnológico no qual são diversos os meios que auxiliam o ser humano a realizar determinadas tarefas no seu cotidiano, assim também como existem aqueles que desenvolvem a função de entretenimento.

Segundo Maria Lucia Lemme Weiss (1992, p. 4) “[...] triste é a escola que não acompanha o mundo de hoje, ignorando aquilo que seu aluno já vivencia fora dela [...]", pois a evolução científica e tecnológica geralmente é apreendida pelas crianças e adolescentes "rapidamente", chegando até elas na grande maioria das vezes pelos meios de comunicação que se encontram disponíveis socialmente. Nesse cenário informacional e comunicacional, em nosso cotidiano e por meio de nossas experiências, observamos que a criança carrega dentro de si uma curiosidade inata e natural por conhecer o mundo à sua volta. Ela se vê rodeada por todo esse ambiente, descobrindo realidades diferentes e incorporando diversos tipos de conhecimentos que muitas vezes extrapolamo conhecimento dito escolar. Em contrapartida, de forma geral, a instituição escolar em seu conjunto (estrutura/organização física, organização curricular, metodologia, entre outros) perto das novas tecnologias, adquire um caráter antigo e ultrapassado.

Diante do contraste entre escola e mídia, torna-se necessário repensar as metodologias utilizadas em sala de aula, sendo importante que direcionemos os nossos olhares para os meios que vêm ocupando o espaço e a preferência das crianças. Como sujeitos da educação que constituímos e ao mesmo tempo somos constituídos, devemos levar em consideração os múltiplos fatores que de alguma maneira interferem na educação e na aprendizagem dos educandos, no que se refere tanto ao aspecto escolar quanto ao conhecimento informal, ou seja, aquele que aprendemos e utilizamos no cotidiano.

Nesse sentido, Priscila Kalinke da Silva (2012, p. 45) argumenta sobre a importância de pais e educadores realizarem de forma adequada uma educação voltada para os meios que possibilitem o desenvolvimento da competência crítica e reflexiva das crianças e jovens. Segundo a autora, a mediação não é um trabalho a curto prazo, devendo ser uma prática constante no processo de educação para que se formem sujeitos críticos do processo de comunicação. A instituição escolar, nesse âmbito, constitui-se como um

[...] local profícuo para este processo de mediação, contanto que haja esforço dos agentes escolares para uma prática pedagógica que vise à produção crítica e criadora do aluno. É, ainda, neste local, onde as discussões sobre temas cotidianos dos alunos - como a mídia - são realizadas, seja dentro da sala de aula, ou no pátio da escola [...].

Os professores devem fazer dos meios de comunicação seus aliados no processo de ensino e aprendizagem. Entretanto, observase certa resistência de "[...] muitos professores na utilização da mídia como recurso pedagógico, ou o emprego equivocado dos meios, como por exemplo, para substituir um professor que faltou na escola [...]" (SILVA, 2012, p. 42). Realizar a educação para os meios se constitui um desafio tanto para os pais quando para os educadores, os quais devem estar atentos aos meios e aos conteúdos que as crianças têm acesso, uma 
vez que, como demonstra Mendes (2006), os jogos eletrônicos converteram-se em artefatos que tomaram certa força social, cultural e econômica, pois estão envolvidos com o markentig, o consumo, a mídia e a Internet, mas também com a escola, a educação e com o nosso cotidiano, enfim, com a nossa vida. Assim, a maneira como o conhecimento é adquirido e disseminado na atualidade termina por assumir outras características, uma vez que a tecnologia se torna um dos veículos de acesso.

Autores como E. Y. Kashiwakura (2008) defendem que os jogos eletrônicos permitem o desenvolvimento de competências cognitivas nos indivíduos, auxiliando na aprendizagem de outros idiomas como, por exemplo, o inglês, entre outras possibilidades. Enfim, os jogos eletrônicos auxiliam o sujeito na construção do conhecimento ao mesmo tempo em que o levam ao entretenimento jogando e superando os desafios. Como demonstra Kashiwakura (2008, p. 29)

[...] Em termos mais específicos, o conceito de jogo pode ser relacionado com o lúdico, com um sistema de regras formais, com a capacidade humana de brincar, tornando assim um instrumento que faz com que os jogadores adquiram conhecimento e aprendizado [...].

Os sujeitos constroem as mais heterogêneas relações com os jogos eletrônicos, uma vez que estes educam quem joga de alguma maneira (MENDES, 2006). Assim, são criados e recriados diversos sentidos e interpretações pelo jogador, o qual se apropria dos conteúdos e informações presentes nos jogos de diferentes formas. Desse modo, cada indivíduo apropria-se dos discursos contidos nos jogos de maneiras distintas.

Tendo em vista a discussão, os argumentos de Postman (1999) sobre o desaparecimento da infância relacionando o fenômeno às mídias devem ser problematizados. Como demonstra Fernanda dos Santos Rocha (2012, p. 5), a TV, especialmente os desenhos animados e os outros meios comunicacionais, não devem ser considerados os "vilões" da história, já que "[...] não determinam comportamentos, dependendo, antes, da leitura de cada indivíduo no interior de certos contextos históricos [...]". A autora discute a apropriação do discurso midiático feito por um grupo de vinte e duas crianças. Segundo os resultados obtidos pela autora, as crianças não são "seres" alienados a tudo aquilo que a mídia lhes impõe. Pelo contrário, assistem desenhos animados, mas também brincam, estudam, passeiam e leem livros, construindo e reconstruindo sentido sobre as informações que têm acesso. Ou seja, os indivíduos, em específico as crianças, não são seres passivos que apenas recebem os conteúdos "prontos e acabados": elas também são leitoras dos mesmos, selecionando programas, desenhos, filmes, seriados, jogos, roupas, brinquedos, enfim, os produtos que querem consumir.

\section{Procedimentos metodológicos}

Tendo em vista essa discussão, para a realização da investigação científica, foram utilizadas como amostra trinta e um estudantes de aproximadamente 6 a 9 anos de idade que estudam em uma escola de Ensino Fundamental, os quais atendiam aos requisitos solicitados para a pesquisa, ou seja, participaram voluntariamente, tendo acesso aos videogames e/ou jogos eletrônicos e com a permissão de seus responsáveis. Com estes alunos foi desenvolvido um estudo de caso a partir da aplicação de entrevistas semiestruturadas para que ocorresse maior interação com os entrevistados sendo os 
dados coletados e analisados por meio de tratamentos qualitativos. Esse tipo de entrevista permite que o pesquisador estabeleça um diálogo "aberto" com os entrevistados sem se prender a um questionário fechado, permitindo que a entrevista possa ser adaptada de acordo com as eventuais informações que sejam encontradas no decorrer da investigação. É válido recordar que a execução da pesquisa foi aprovada pelo Comitê de Ética da Universidade Estadual de Maringá, pelo processo $n^{\circ} 4870 / 2011$.

A coleta de dados foi realizada na biblioteca da escola, por meio de observações e conversas com as crianças. O conteúdo da entrevista foi gravado com gravador de som digital e posteriormente transcrito. $\mathrm{O}$ trabalho ocorreu no período da tarde em duas semanas devido à grande quantidade de crianças e à metodologia escolhida, uma vez que a entrevista semiestruturada exige do investigador mais atenção às respostas fornecidas pelos alunos, pois, apesar da utilização do questionário nas entrevistas, as perguntas devem ser flexíveis, adequandose às respostas dos entrevistados sempre que necessário para que não haja um direcionamento enviesado por parte do pesquisador. Assim, priorizou-se a concessão de liberdade aos discentes entrevistados para que expressassem suas opiniões sobre as questões envolvendo os jogos eletrônicos.

A escolha pelo período vespertino ocorreu devido à oferta de um público jogador maior e mais diversificado em relação à faixa etária, uma vez que neste período só estudam crianças que moram no distrito e por isso têm mais tempo para dedicarse aos jogos eletrônicos. O fato de ter trabalhado na instituição em 2010 também me ajudou a tomar essa decisão, uma vez que conhecia os professores, funcionários e a maioria das crianças que foram entrevistadas, tendo também o conhecimento dos comportamentos e desempenho escolar destes últimos. Desse modo, não foi difícil estabelecer diálogo com as crianças, os professores e a equipe pedagógica.

Notou-se grande interesse por parte dos alunos em participarem das entrevistas, pois alguns deles acharam que iriam jogar jogos eletrônicos na escola e outros ainda decidiram participar depois que se iniciou a coleta de dados devido aos comentários dos seus colegas de sala relatando as experiências. Dessa forma, pode-se perceber que as entrevistas despertaram o interesse e a curiosidade das crianças, pois mesmo após o encerramento da pesquisa alguns alunos que me viam na escola ou na rua perguntavam quando eu voltaria para entrevistá-los novamente.

Alguns dos questionamentos realizados foram os seguintes: quais jogos os alunos têm acesso; quanto tempo dedicam a essa atividade diariamente; o que mais gostavam nos jogos eletrônicos; se os pais jogavam com eles ou só os observavam, entre outras indagações. Lembra-se que, no decorrer das entrevistas, algumas questões foram alteradas e mesmo surgiram outras de acordo com as informações recebidas.

\subsection{Análise das entrevistas}

$\mathrm{Na}$ tabela a seguir se encontram a série, a idade, a quantidade e o total de crianças que compuseram a amostra para esta pesquisa: 


\begin{tabular}{|l|l|l|}
\hline \multicolumn{2}{|l|}{ Tabela 1 - Série escolar, faixa etária e quantidade de crianças entrevistadas } \\
\hline Série & Faixa etária (anos) & Quantidade de crianças \\
\hline $1^{\circ}$ ano & 5 & 2 \\
& 6 & 9 \\
\hline $2^{\circ}$ ano & 7 & 7 \\
\hline $3^{\circ}$ ano & 8 & 4 \\
\hline $4^{\circ}$ ano & 9 & 9 \\
\hline & & Total: 31 \\
\hline
\end{tabular}

Os jogos eletrônicos citados pelos entrevistados foram "jogos de vestir roupas na boneca", "corrida de carros, de motos e de bicicleta", "montar carros", "Hot Weels", "Bob Esponja", "Batman e Robin", "Ben 10", "jogo de caminhonete de rally", "jogo de robô e de dinossauro", "GTA", "Mario Bros", "jogos de luta", "Futebol", "Guitar Hero", "Resident Evil", "WWE", "lutas marciais", "jogos de skate", "jogo de sinuca", "aluno e professor", "jogo do Sítio do Pica-Pau Amarelo", "Scooby Doo", "Crash" e "Transformers", entre outros. Percebe-se que certos alunos não citam os nomes dos jogos propriamente ditos, mas o gênero de forma geral. Além disso, esses games são jogados em diferentes plataformas, como videogames propriamente ditos, computadores e celulares, entre outros dispositivos.

\section{O jogo eletrônico mais citado} foi "GTA", sigla para "Grand Theft Auto", disponível em computadores e consoles. Atualmente, existem várias versões do game. Segundo Nadja Carvalho e Daniel Abath (2010, p. 38), o jogo é famoso

[...] pela prevalência de temas politicamente incorretos e por representações da vida urbana norte-americana. No currículo de sua produtora, a Rockstar Games, figuram jogos como Bully, ou mesmo o sanguinário Manhunt, título proibido em diversos países no mundo, atestando a preferência da desenvolvedora por abordagens da violência, assédios morais, psicopatias e realidades socioculturais em seus jogos.
O título Grand Theft Auto significa, em português, "grande ladrão de carros", remetendo-se diretamente à principal característica do jogo: a possibilidade, desde o GTA 1 lançado para computador, até o atual GTA IV, de roubar carros presentes no espaço virtual. Com a evolução das versões, o criminoso protagonista (o avatar) pode, além de roubar, matar, agredir e transgredir as leis e normas sociais em ambientes urbanos. Por esses motivos, o game tem classificação adulta e costuma ser taxado como dispositivo de influência às más condutas.

Apesar de alguns jogos mencionados, como "GTA" e "Resident Evil", apresentarem conteúdos inadequados para as crianças, nenhuma delas afirmou que se tratava de um jogo violento ou algo similar. Somente três alunos de nove anos mencionaram a violência durante a entrevista. Segundo eles (SANTOS, 2012): "[...] Tem uns jogos de skates que nos ensina manobras e uns de lutas que ensinam muitas coisas más, mas eu não gosto deles muito não [...]". Segue o diálogo com o outro aluno (SANTOS, 2012):

Entrevistadora: Você gosta de jogar videogames?

Aluno: Mais ou menos.

E: Por que mais ou menos?

A: Por que eu acho que alguns têm muita violência.

E: Têm muita violência?

A: Tipo de tiro. (...)

E: Quem que falou pra você que o videogame é violento?

A: Por que meu pai baixou um joguinho daí eu sei. 

E: Aí você vê ele jogando?
A: Aham.
E: É de tiro, de matar as pessoas?
A: É.
E: Mas por que você acha violento?
A: Porque, aí porque eles vai e mata a pessoa.

Notou-se nas entrevistas, que esses alunos desenvolveram certos valores em torno do "certo" e do "errado", para eles a violência é algo "ruim". Apesar disso, percebeu-se que as crianças entrevistadas selecionam os jogos eletrônicos de acordo com aquilo que acreditam ser o "mais legal" e/ou divertido. As outras crianças que afirmaram jogar os mesmos jogos ou similares, em momento algum mencionaram que eram violentos. Ao contrário, disseram que é "[...] Muito legal [...]"; " "[...] Todo joguinho não é violento, todos são legais [...]" (SANTOS, 2012).

Observa-se que as crianças não se assustam com as cenas de violência, com os "zumbis" ou monstros presentes nos jogos. Algumas delas falaram com muita naturalidade sobre esses tipos de jogos como se estivessem falando sobre qualquer outro assunto. Cabe levantarmos os seguintes questionamentos: elas não teriam construído uma noção de violência? Ou viveriam num mundo tão violento que os jogos eletrônicos perdem seu impacto? Os jogos virtuais são considerados irreais e, portanto, não efetivamente violentos?

Outra criança de nove anos, ao ser questionada sobre um jogo considerado "violento", afirmou que seu jogo predileto era "Resident Evil". A série, criada pela CAPCOM para uma série de plataformas, desde videogames a computadores, enfoca ambientes nos quais pessoas são infectadas por vírus, tornando-se zumbis (nos três primeiros títulos da série), ou por parasitas, perdendo a sanidade (nos três últimos jogos). "Resident Evil" envolve uma atmosfera de suspense, terror e ação, perpassado por grau significativo de violência.

Retornando à entrevista, segue o diálogo entre a autora e o aluno:
E: E qual é o seu preferido?
A: Resident Evil.
E: Por quê?
A: Por que tem que ajudar, tem vez que tem que ajudar cachorro, tem vez que tem ajudar as pessoas, tem que matar o zumbi.
$\mathrm{E}$ : Você acha legal matar zumbi?
A: Sim.
E: É, por que você acha legal matar zumbi?
A: Por que tem que ajudar as pessoas (SANTOS, 2012).

Observou-se que a criança não considera errado "matar zumbis" no jogo, uma vez que ao fazer isso estaria "ajudando as pessoas", além de seguir as regras e objetivos. A respeito disso Rayner Lacerda (2012, s.d.) afirma que
[...] games como o já citado GTA, contribuem para que o seu filho, desde pequeno, desenvolva noções de certo e errado. Por mais que ele se divirta atropelando pedestres e assaltando bancos no mundo virtual, desligou- se o console e pronto, a vida continua, só que muito mais divertida [...].

Lacerda (2012) e Carlos William Ferreira de Lima (2008, p. 22) defendem que a prática dos jogos eletrônicos é uma atividade divertida, saudável e prazerosa, pois se constitui em "[...] elemento de diversão, aprendizado e ligação entre indivíduos [...]". Além disso "[...] os videogames servem como uma espécie de válvula de escape para a agressividade, e não como mola propulsora [...]" (LACERDA, 2012, s.p.). Entretanto, quando as crianças não conhecem outras formas de se divertir além dos jogos eletrônicos ou não sabem diferenciar entre a realidade e a fantasia, nesses casos podem surgir problemas. Torna-se fundamental que 
pais ou responsáveis orientem as crianças de forma adequada. O professor também desempenha papel fundamental nesse processo, uma vez que

[...] a escola não se reduz apenas a um lugar de aprender, mas é um local de crescimento, um espaço de experimentar conhecimentos e integrá-los aos conhecimentos já existentes para saber utilizá-los em situações específicas da vida prática [...] (NEGRÃO, 2010, p. 76).

A respeito disso, Orozco argumenta sobre a necessidade de se educar para os meios midiáticos. Segundo o autor, essa educação deve ser alcançada pelo processo de mediação pedagógica em relação às mídias, que "[...] deve ser realizado entre os meios de comunicação, as instituições educativas e os processos de recepção de mensagens que envolvem os estudantes [...]" (OROZCO apud SILVA, 2012, p. 36), visando desenvolver a autonomia crítica do aluno, valorizando a reflexão e o diálogo, com o objetivo principal de educar para a cidadania, possibilitando aos educandos o conhecimento de seus direitos, permitindoIhes refletir sobre sua realidade e atuando como protagonistas sociais. Nesse sentido, os pais e os educadores devem estar atentos ao assunto, abandonando preconceitos e buscando conhecer mais sobre as mídias eletrônicas, para que possam orientar as crianças da melhor maneira possível.

Das trinta e uma crianças entrevistadas, somente quatro afirmaram que deixam de estudar para jogar, levando-nos a refletir sobre a função dos pais ou responsáveis que deveriam atentar para questões como essa. Uma criança ainda afirmou que seus pais não "ligam" muito para os jogos que ela joga. Somente oito das crianças afirmaram que os seus pais (a mãe, o pai ou os dois) jogam com eles e observam que tipo de jogos estão jogando, o restante afirmou que jogam com parentes e/ou amigos. Ou seja, embora o acompanhamento dos responsáveis seja fundamental, isso foi indicado por apenas um terço dos entrevistados. No decorrer da entrevista, pode-se constatar que a maioria dos pais ou responsáveis pelas crianças, possivelmente em virtude do trabalho, não têm muito tempo disponível para dedicarem a atenção adequada às crianças. Como nos relatou uma criança de seis anos: " $\mathrm{E}$ : Os seus pais jogam com você? A: Não, eles têm muita coisa pra fazer [...]" (SANTOS, 2012).

A respeito disso Barros (2009, p. 94) argumenta que

Quando esses pais contemporâneos retornam de seus trabalhos, já cansados e muitas vezes irritados, não dão conta de mediar as informações que seus filhos adquirem na escola, nos meios de comunicação e na própria convivência social. Além disso, o tempo gasto com os filhos diminuiu significativamente. Entretanto, o que queremos refletir não é sobre a quantidade de tempo e sim a qualidade, isto porque é sabido que devido às transformações econômicas é quase impossível que [se] consiga passar tempo integral com os filhos. O tempo que a maioria das famílias separa para conviver com seus filhos é muitas vezes emprestado à televisão e ao computador e, quase sempre, cheio de lamentações.

Portanto, deve-se observar o contexto histórico, social e econômico no qual as famílias estão inseridas. É preciso compreender o porquê dos responsáveis agirem de determinada maneira: eles não dedicam tempo e atenção adequadas aos filhos somente porque querem? Não se está afirmando que o meio determina o comportamento e escolhas do indivíduo, mas que existem inúmeras dificuldades cotidianas para que os sujeitos desenvolvam suas funções de pais e mães com qualidade. Entretanto, apesar de constituir empecilho, 
isso não deve se converter em pretexto para justificar a ausência na educação dos filhos. Não há como deixar de lado ou ignorar a questão, uma vez que a família desempenha função essencial para a construção do sujeito, isto é, dos seus hábitos, costumes, crenças, atitudes e comportamentos. Juntamente a ela, principalmente a escola, a religião e os círculos de amizades vêm complementar essa construção, permitindo que o indivíduo tenha contato com outras culturas, com outras formas de enxergar, ser e agir no mundo. Segundo Barros (1987, p. 55), "[...] os pais e as condições do lar moldam a criança em seus primeiros anos de vida [...]".

A família representa base fundamental sobre a qual a criança irá se apoiar, construindo a sua personalidade e desenvolvendo as suas relações com o mundo que a cerca, consigo mesma e com as pessoas que tem contato. Refletindo sobre essas questões, no decorrer da aplicação das entrevistas, pode-se constatar que os jogos também se constituem como elemento de socialização. Como demonstra E. Y. Kashiwakura (2008, p. 19),

[...] No mundo dos videogames, alguns jogos impõem a seus jogadores a necessidade de busca pelo conhecimento para que possam vencer os desafios que lhes são apresentados. Desta forma, eles acabam desenvolvendo habilidades cognitivas.

Os jogadores procuram interagir com o seu círculo de amizades, pesquisando, descobrindo, respeitando regras, abrindo portas, coletando dicas que os games fornecem, lendo revistas, listas, sites, fórum, emails e blogs [...].

Observou-se especialmente que parte significativa das crianças imita alguns personagens de jogos eletrônicas nas brincadeiras que realiza dentro e fora do ambiente escolar. Nota-se também, por meio das entrevistas, que os jogos eletrônicos constituem uma brincadeira contemporânea que vem ganhando cada vez mais espaço e preferência principalmente no público infanto-juvenil. Brincadeira que pode ocorrer tanto pelo ato de jogar os jogos eletrônicos em computadores ou pelos videogames propriamente ditos, quanto pela transposição dos jogos para as brincadeiras tradicionais, como as mencionadas pelos alunos.

Um educando afirmou que joga "[...] só por diversão [...]" (SANTOS, 2012), já outra aluna postulou que gosta mais de jogar " $[. .$. porque a televisão não tem nada o que fazer" (SANTOS, 2012), isto é, não permite que ela participe como acontece nos jogos. Percebese, neste trecho, que a aluna está aludindo à possibilidade de interatividade inexistente ou limitada nas mídias tradicionais, como a televisão e o rádio. A interatividade configura-se em uma tendência dos meios de comunicação atuais, especialmente com a chamada Web 2.0, que aumenta a interatividade com o usuário e possibilita a cada leitor tornar-se autor, produzindo mensagens e não somente consumindo-as (SILVA, 2012). Segundo Lima (2008, p. 99),

[...] É a interatividade que possibilita ao gamer participar da história e definir rumos para que alcance seus objetivos dentro do jogo, sejam eles conquistar pontos, ganhar corridas, derrotar inimigos ou mesmo fingir ser um personagem desvendando os segredos do jogo durante o tempo em que participa dele [...].

A interatividade possibilita também ao jogador mudar os rumos de seu personagem. Isso garante que as suas decisões sejam apresentadas na tela do jogo, definindo se o jogador irá conseguir conquistar os objetivos do jogo ou não: "[...] sem essa interação de jogador e personagem o jogo não se processa [...]" (LIMA, 2008, p. 100). Essa interatividade vem aumentando nas novas gerações de consoles e jogos 
que são lançados no mercado. Os sons presentes nos jogos também são elementos importantes, pois estes aumentam a sensação de imersão, ressaltando o realismo das cenas e integrando-se à visualidade dos gráficos. Assim, o jogo se torna uma experiência mais realista se comparado com mídias como a televisão e o rádio.

Outro elemento essencial nos jogos eletrônicos diz respeito à sua narrativa, que geralmente possui começo, meio e fim. Deste modo, "[...] o jogo pode ser uma forma de contar uma história, respeitando as regras [...]" (LIMA, 2008, p. 107) mencionadas. Aos gamers é "[...] dada a possibilidade de construir passo a passo a história, ao mesmo tempo em que traz o desafio do jogo em que o faz de conta, a simulação e a narrativa dividem espaço [...]" (LIMA, 2008, p. 108).

Outro aluno afirmou que prefere assistir televisão e estudar a jogar jogos eletrônicos, contudo ele alegou que gosta de jogar e que considera esta atividade como um "passatempo". Quando "[...] não tem nada, não tem o que fazer [...]" (SANTOS, 2012) ele joga. Sobre a questão dos jogos eletrônicos serem ou não educativos, apenas três alunos de nove anos souberam explicar e exemplificar suas opiniões. Um deles afirmou que aprende manobras de skate por meio da imitação do jogo. Neste caso o aluno imita as manobras do jogo.

As respostas sugerem que as crianças não são "seres" alienados a tudo aquilo a que têm acesso por meio das mídias eletrônicas. Pelo contrário, elas assistem desenhos animados, jogam jogos eletrônicos, mas também brincam, estudam, passeiam e leem livros, construindo e reconstruindo sentido sobre as informações que acessam. De acordo com Silva (2012, p. 36)

[...] A recepção, portanto, consiste em um processo no qual os sujeitos são agentes ativos no processo de comunicação, atuando mais que receptores, mas produtores e autores, não se restringindo a receber mensagens passivamente, como se fossem meros consumidores do produto produzido pelo emissor, sem produzir estímulos algum.

Os meios de comunicação se constituem como campos simbólicos de interação pelos quais os sujeitos constroem e compartilham significados. Segundo Silva (2012, p. 36), " [...] esse processo de interação se realiza ainda por meio de narrativas e as significações propiciadas por elas, configurando-se como um campo de ações que possibilitam a aprendizagem [...]". Nesse sentido, Gardner (apud KASHIWAKURA, 2008, p. 51 e 52) afirma que "[...] cada indivíduo possui uma maior ou menor capacidade de inteligência desenvolvida [...]", as quais são classificas em sete grupos, sendo eles: Lógico-Matemática, Linguística, Musical, Espacial, Corporal-Cinestésica, Interpessoal e Intrapessoal. De acordo com Kashiwakura (2008), a escola deve auxiliar a desenvolver essas inteligências, valorizandoas na aprendizagem. Segundo ele, o uso de videogames desenvolve habilidades visuais, motoras, aprimoramento da autoestima, responsabilidade, interpretação de textos, sociais, liderança, concentração e raciocínio.

\section{Considerações finais}

Os jogos eletrônicos têm sido culpados pelos "maus comportamentos" expressos pelas crianças segundo o senso comum. Eles não são "inocentes" e seria inadequado afirmar que o público infantil possa jogar qualquer título independente do conteúdo ou da classificação etária. Recomenda-se, antes, que sejam respeitadas as classificações e que 
os conteúdos dos jogos sejam bem analisados pelos pais e que os mesmos façam a mediação de toda essa informação que seus filhos têm disponível. Apesar dessas recomendações (cabíveis, aliás, a qualquer tipo de mídia, inclusive os livros), os jogos eletrônicos contribuem para o desenvolvimento de habilidades como aquelas citadas por Kashiwakura (2008). Eles não podem ser considerados "os grandes vilões da história", já que qualquer conteúdo midiático não determina comportamentos, uma vez que os receptores apropriam-se de forma ativa das informações, construindo sentidos e convertendo-os em práticas de maneiras diferenciadas. Por isso, as relações com os jogos eletrônicos devem ser compreendidas, problematizadas e avaliadas juntamente às demais relações que os envolvem e à constituição do ser humano.

Como visto, é essencial questionar o papel da família, uma vez que ela é ou deveria ser responsável pela formação das crianças, devendo mediar os conteúdos aos quais têm acesso. Os pais ou responsáveis têm por obrigação acompanhar os jogos eletrônicos que seus filhos ou dependentes jogam, conversando com eles e ensinandoos. Também é fundamental que os pais e professores desenvolvam uma mediação voltada para os conteúdos que as crianças têm acesso, divisando realidade e fantasia e discutindo valores.

A ausência familiar deve ser compreendida em seu contexto histórico, social, econômico, político e cultural. Para Barros (2009, p. 94), "[...] atualmente, $90 \%$ das famílias se ajustam a uma nova concepção estrutural, em que pais e mães deixam seus filhos com outros para enfrentar o mercado de trabalho [...]". Número significativo dos pais por vezes não consegue participar da vida de seus filhos como gostariam. Contudo, motivos como esses não devem se transformar em pretextos para a omissão dos pais frente às questões discutidas ao longo deste trabalho. Como afirma Barros (2009), o segredo não está no tempo disponível, mas na qualidade dos momentos que a agenda de cada família permite. Os pais não são os únicos responsáveis pelo comportamento de seus filhos, bem como ao conteúdo que os mesmos têm acesso, mas sua atuação é importante para a construção da personalidade, dos hábitos e crenças da criança.

Por meio das entrevistas constatou-se que os jogos eletrônicos são uma "brincadeira contemporânea" para as crianças e que, apesar de algumas terem pouca orientação dos pais sobre o assunto, apropriam-se de diversas maneiras dos conteúdos abordados. Observarmos ainda que, salvo exceções, as influências exercidas pelos jogos eletrônicos não têm refletido negativamente no comportamento escolar dos alunos, pois os mesmos não colocam os jogos eletrônicos como prioridade em seu cotidiano, mas outras atividades como brincadeiras e os estudos. Destaca-se a importância do uso dos videogames, bem como de sua análise e problematização contemporaneamente, já que existem estudos (KASHIWAKURA, 2008) voltados para este assunto, demonstrando como o instrumento midiático pode contribuir de maneira positiva para a aprendizagem e o desenvolvimento de competências dos educandos. Por fim, acrescenta-se que o presente estudo foi apenas um recorte do amplo leque que envolve mídia, educação e sociedade. Sem esgotar o assunto, espera-se que esta pesquisa desperte o interesse para os jogos eletrônicos, por parte de pais, professores e pesquisadores.

\section{Referências}

BARROS, Marta Silene Ferreira. A importância da família no processo de formação e desenvolvimento da criança na idade escolar. In: CAMARGO, Janira Siqueira; ROSIN, Sheila Maria (orgs). Psicologia da educação e os processos de aprendizagem de aprendizagem e de desenvolvimento. 2. ed. Maringá: EDUEM, 2009. 
BOOK, Ana Mercês Bahia. A perspectiva sócio-histótica de Leontiev e a crítica à naturalização da formação do ser humano: a adolescência em questão. Caderno CEDES, v. 24, n. 62, Campinas, 2004.

BOOK, Ana Mercês Bahia; FURTADO, Odair; TEIXEIRA, Maria de Lourdes Trassi. Psicologias: uma introdução ao estudo de psicologia. In: BOOK, Ana Mercês Bahia (org.). Identidade. 13. ed. São Paulo: Saraiva, 2002.

CARVALHO, Nadja; ABATH, Daniel. A comunicação cotidiana em GTA IV: estudo de ambiências lúdicas na realidade virtual. 2010. Disponível em: < http://www.cchla. ufpb.br/ppgc/smartgc/uploads/arquivos/ f1b4b9d6ca20101112105126.pdf > . Acesso em: 10 jun. 2012.

CHARTIER, Roger. A História Cultural: entre práticas e representações. Lisboa, Rio de Janeiro: Difel, Bertand Brasil, 1990.

(org.). Práticas de leitura. 2 ed. São Paulo: Estação Liberdade, 2001.

INTERNET WORLD STATS. Usage and Population Statistics. Disponível em: < http:// www.internetworldstats.com/stats.htm > . Acesso em: 10 nov. 2011.

KASHIWAKURA, E. Y. Jogando e aprendendo: um paralelo entre videogames e habilidades cognitivas. 2008. Dissertação (Mestrado em Tecnologia da Inteligência e Design Digital) Pontifícia Universidade Católica de São Paulo, São Paulo. 2008.

LACERDA, Rayner. Analógico: videogames, por que as crianças precisam brincar de matar monstros? 2012. Disponível em: < http:// www.playstationblast.com.br/2012/06/ analogico-videogames-porqueas.html > . Acesso em: 10 jun. 2012.

LIMA, Carlos William Ferreira de. A construção da imagem realista em jogos de videogame: um estudo sobre as representações imagéticas nos games de nova geração. 2008. Dissertação (Mestrado em Comunicação e Semiótica) Pontifícia Universidade Católica de São Paulo, São Paulo. 2008.

MARTÍN-BARBERO, Jesús. Saberes hoje: disseminações, competências e transversalidades. In: RIBEIRO, Ana Paula Goulart; HERSCHMANN, Micael (Orgs.). Comunicação e História: interfaces e novas abordagens. Rio de Janeiro: Mauad X, Globo Universidade, 2008.

MENDES, Cláudio Lúcio. Jogos eletrônicos: diversão, poder e subjetivação. Campinas: Papirus, 2006.

NEGRÃO, Maria Tampellin Ferreira. Processo escolanovista. In: ALTOÉ, Anair; GASPARIN, João Luiz; NEGRÃO, Maria Tampellin Ferreira; TERUYA, Teresa Kazuko (orgs). Didática: processos de trabalho em sala de aula. 2. ed. Maringá: EDUEM, 2010.

OLIVEIRA, Vera Barros de (Org.). O brincare a criança do nascimento aos seis anos de idade. Petrópolis: Vozes, 2000.

POSTMAN, Neil. O desaparecimento da infância. Rio de Janeiro: Grapha, 1999.

RIDOLFI, Aline. Crianças brasileiras lideram ranking de acesso à internet. 2010. Disponível em: < http://revistacrescer.globo.com/ Revista/Crescer/0,,EMI128629-10587,00. html > . Acesso em: 22 mar. 2012. 
ROCHA, Fernanda dos Santos. Interfaces entre a mídia e a infância: as influências dos desenhos animados sobre o comportamento infantil em ambiente escolar. 2012. Relatório (Programa de Iniciação Científica) Universidade Estadual de Maringá, Maringá. 2012.

SANTOS, Adriély da Silva. Entrevistas realizadas com alunos de uma escola de Ensino Fundamental de São Lourenço, distrito de Cianorte (Paraná). 2012.

SERTZER, Valdemar W. Efeitos negativos dos meios eletrônicos em crianças, adolescentes e adultos. 2011. Disponível em: < http:// www.ime.usp.br/ vwsetzer/efeitos-negativosmeios.htm > . Acesso em: 22 mar. 2012.

SILVA, Priscila Kalinke da. Educação escolar e desenho animado japonês: em estudo o animê Naruto. 2012. Dissertação (Mestrado em História e Historiografia da Educação) Universidade Estadual de Maringá, Maringá. 2012.

STEINBERG, Shiley R.; KINCHELOE, Joe L. (orgs.) Cultura infantil: a construção corporativa da infância. 2. ed. Rio de Janeiro: Civilização Brasileira, 2004.

THOMPSON, Paul. A voz do passado: história oral. 2 ed. Rio de Janeiro: Paz e Terra, 1998.

WEISS, Maria Lucia Lemme. Psicopedagogia clínica: uma visão diagnóstica. Porto Alegre: Artes Médicas, 1992.

\section{(Endnotes)}

1 A pedagogia cultural diz respeito à análise da produção corporativa da cultura infantil e seu impacto nas crianças. As áreas pedagógicas referem-se aos meios nos quais o saber/ poder é organizado e difundido, incluindo-se programas televisivos, bibliotecas, revistas, propagandas, videogames, livros e filmes. 2 Por apropriação, compreende-se as diferentes formas como os leitores, em sentido amplo, interpretam e, portanto, apropriam-se das representações inscritas em diferentes linguagens, dos textos escritos às imagens (CHARTIER, 2001). As representações, por sua vez, remetem às ideias e sentimentos (re) construídos por grupos sociais em determinados contextos históricos que podem ser veiculados de diferentes formas (CHARTIER, 1990). Portanto, representações e apropriações inseremse num círculo orgânico de produção e leitura. 
